\title{
'Honeytrapping' Pseudomonas From Water: A Sustainable Prototype For Water Disinfection
}

\section{Hemangi Ranade}

Amity University Rajasthan: Amity University - Jaipur Campus

\section{Priya Paliwal}

Amity University Rajasthan: Amity University - Jaipur Campus

Debarati Paul

Amity University

Manali Datta ( $\nabla$ mdatta@jpr.amity.edu )

Amity University Rajasthan https://orcid.org/0000-0002-5335-3446

\section{Research Article}

Keywords: Chemoattractant, Honey, Inhibition, Pseudomonas, Water treatment

Posted Date: July 16th, 2021

DOl: https://doi.org/10.21203/rs.3.rs-708185/v1

License: (c) (i) This work is licensed under a Creative Commons Attribution 4.0 International License. Read Full License 


\section{Abstract}

This paper introduces a novel prototype for the removal of Pseudomonas from water samples. Bacterial cells have the tendency to get attracted towards specific chemicals (chemotaxis); a 'honeytrap' strip was conceptualized by integrating a combination of serine, pseudomonas specific chemo-attractant and honey to attract and inhibit the bacteria in situ. Honey, a natural antimicrobial agent, has garnered attention in its effective inhibitory role in Pseudomonal biofilms and wound infections. Dipping serine side of the strip attracted bacteria towards honeytrap, wherebythe porous nature of the strip facilitated the 'trapping' and subsequent diffusion of the bacterial cells towards honey-adsorbed end of the strip. This 'honeytrap' reportedly leads to the targeted elimination of Pseudomonas, hence facilitating its removal. The percentage efficacy of this 'honeytrap' device is $96 \%$ with a log reduction equivalent to 1.6 within a time frame of 2 hours. Pseudomonas aeruginosa, although, not a natural contaminant of potable water, enters circulation due to improperly maintained plumbing fixtures and storage facilities. Honeytrap strip is an easy to use, biodegradable and cost effective sustainable solution, and thus a scaled up version ofthis device may enablesubstantial improvement in quality of potable water.

\section{Introduction}

Consumption of contaminated water affects the health of approximately 1.8 billion people all over the world. Bioaccumulation of non-degradable contaminants has aggravated the intensity and propensity of fatal diseases(Jamshaid et al., 2018). Potability of water is decided by the physicochemical and biological parameters according to World Health Organization (WHO)(Galal-Gorchev, 1993; Van Leeuwen, 2000), Environment Protection Agency (EPA)(Oberdiek, 2007), Environment Quality Standard (EQS) (Gobelius et al., 2018). Although comprehensive water testing mechanisms ensure that international standards for water quality are stringently met, yet local contaminations during storage and distribution have been observed resulting in increase in bacterial load(Brick et al., 2004; Han et al., 1989). One of the major concern is that water acts as a reservoir and aids easy transmission of pathogens like Pseudomonas aeruginosa (P. aeruginosa), Flavobacteriummeningosepticum, Aeromonashydrophilla(Rutala and Weber, 1997). Hence, there is an urgent need for field-applicable devices for testing and sanitization of potable water especially at household levels.

$P$. aeruginosa, an opportunistic, gram negative bacteria is the prominent cause of both community and hospital based infections(Pachori et al., 2019). Currently, sensitive detection of $P$. aeruginosa and its metabolites is based on genotyping techniques such as Polymerase Chain Reaction (PCR)(Héry-Arnaud et al., 2017), Next Generation Sequencing (NGS)(Chen et al., 2018), real-time PCR and colorimetric biosensor(Alhogail et al., 2019).Fitzgerald and DerVartanian(Fitzgerald and DerVartanian, 1969) established that about $0.5 \mathrm{mg} / \mathrm{L}$ of chlorine is capable of removing $99.9 \%$ P. aeruginosa within an hour; but with decreasing chlorine concentration the effectiveness of this treatment diminishes(Price and Ahearn, 1988). Pseudomonas has been detected in the range of $10-2300 \mathrm{CFU} / \mathrm{mL}$ in drinking water and tap water (Mena and Gerba, 2009), with infective load varying upto $10^{9} \mathrm{CFU} / \mathrm{ml}($ George, 1989), which is contrary to the permitted levels set by European Union. 
As of now, no technique is capable of detecting and disinfecting $P$. aeruginosa simultaneously from solutions. In this work, we have proposed and tested a device for sanitizing the potable water against Pseudomonas. Chemo-attractants like sugar and amino acids have been found to pull bacteria(Sourjik and Wingreen, 2012), especially serine which attracts P.aeruginosa(Moulton and Montie, 1979). Several naturally occurring non-toxic materials such as coffee(Martínez-Tomé et al., 2011),turmeric oil(Negi et al., 1999),capsicum extract(Careagaet al., 2003),moringa leaf extract(Peixoto et al., 2011),honey (Cooper et al., 2002; Shenoy et al., 2012; Wilkinson and Cavanagh, 2005) have been established as inhibitors of $P$. aeruginosa.

Our approach of device fabrication uses a combination of serine as chemoattractant and honey as an inhibitor for removal of $P$. aeruginosa,hence the name, honeytrap. The attractant lures bacteria instantly followed by diffusion of the cells through the contact surface, exposing it to the inhibitor, thus reducing the microbial load.

This inexpensive and field-applicable 'honeytrap' has been successfully validated using a combinatorial approach. In the future, honeytrap may find its application in households as a personal pocket water sterilant

\section{Experimental Section}

\section{Materials}

$P$. aeruginosastrain was obtained from IMTech, Chandigarh. Whatman filter papers were obtained from Whatman International Ltd Maidstone England. LB Broth, LB Agar and serine was procured from HiMedia Laboratories Pvt. Ltd. Honey (Dabur Ltd, India) was purchased locally. Safranin dye was procured from $\mathrm{CDH}$. The water used in this study was double distilled water.

\section{Preparation of Serine and Honey strips}

The Whatman filter paper was cut into strips $(60 \mathrm{~mm}$ X $10 \mathrm{~mm})$. Serine solution $(1 \mathrm{mM})$ was prepared with autoclaved distilled water and sterilized using a syringe filter $(0.22 \mu \mathrm{m}$ nylon membrane). The solution was subsequently stored in flat bottom vials. The autoclaved strip was loaded with $2 \mathrm{ml}$ of serine solution. The strip, after an incubation of 1 hour, was removed and air dried in sterile conditions. Serine strips (SS) thus prepared, were used in further experiments. Sterilized strips were similarly used for the preparation of honey strips (HS). About $2 \mathrm{ml}$ of sterilized stock solution ( $25 \%$ honey $\mathrm{V} / \mathrm{V})$ was prepared and paper strips were likewise incubated for an hour to generate HS. Control strips (C) were also designed containing SS on one end and water imbibed on another end.

HS and SS prepared were annexed to each other via biologically friendly glue to attain a serine-honey strip (SHS) containing an attractant on one end and an inhibitor on another end(Dasgupta et al., 2016).

\section{Preparation of artificially spiked water}


Pseudomonas was grown in nutrient broth overnight at $37^{\circ} \mathrm{C}$ with proper aeration in the rotating incubator. The overnight culture was subsequently inoculated in $25 \mathrm{ml}$ fresh broth and $\mathrm{OD}_{600}$ was monitored till 0.123 corresponding to $3 \times 10^{8} \mathrm{CFU} / \mathrm{ml}$ according to the McFarland scale. The culture was centrifuged at $8000 \mathrm{~g}$ for $15 \mathrm{~min}$ and the cell pellet was resuspended in $25 \mathrm{ml}$ distilled filtered water (spiked water). This spiked water was hereafter used for testing the efficacy of honeytrap for removal of Pseudomonal cells.

\section{Chemoattractant potential of SS}

To assess the trapping mechanism of $P$. aeruginosacells by SHS, glass slides loaded with $200 \mu$ of 'spiked' water were horizontally exposed to the SHS (Serine end) for different incubation periods (15min, $30 \mathrm{~min}, 45 \mathrm{~min}, 1 \mathrm{hr}, 1.5 \mathrm{hr}, 2 \mathrm{hr}$ ). Bacterial chemotaxis was monitored intermittently via microscope (Magnus Opto Systems India Pvt. Ltd.) at various time durations. Subsequently, strips were placed on nutrient agar to assess the possible adsorption of $P$. aeruginosaby honeytrap and incubated overnight at $37^{\circ} \mathrm{C}$.

\section{Trapping efficacy of honeytrap}

'Spiked' water sample ( $2 \mathrm{ml})$ containing $P$. aeruginosawas taken and approximately $1 \mathrm{~cm}^{2}$ of honeytrap was dipped into the vials at the serine side. Vials were exposed to different incubation times ( $15 \mathrm{~min}$, 30 min, 45min, $1 \mathrm{hr}, 1.5 \mathrm{hr}, 2 \mathrm{hr}$ ) with SHS and absorbance at $600 \mathrm{~nm}$ was monitored. The change in OD was attributed to the fact that there was a change in the bacterial concentration. Spectroscopic monitoring for the residual bacterial cells $\left(B_{t}\right)$ enabled calculation of the percentage removal of bacterial cells after each incubation interval using the following formula:-

Percentage removal $=B_{0}-B_{t} / B_{0} * 100$

where $\mathrm{B}_{0}=$ number of viable microorganisms before treatment

The logarithmic scale is normally used for convenient calculation of cell number alteration mainly due to some form of antimicrobial treatment(Lee et al., 2014; Müller et al., 2011).Interestingly, the log reductions are converted to percent reduction which allows us to compare and correlate the efficiency of the treatment. Log reduction was calculated as follows:-

Log reduction $=\log _{10}\left(B_{0}\right)-\log _{10}\left(B_{2 h r}\right)$

where $\mathrm{B}_{2 \mathrm{hr}}=$ number of viable microorganisms after treatment

Electrical conductivity has been considered as a criterion to measure the concentration of bacteria in suspension (HARRIS and PATTY, 1949). Hence, serine as a trapping constituent of P. aeruginosawas assessed by measuring the change in electrical conductivity of the suspension post incubation periods. Briefly, 2 ml 'spiked' water samples were incubated with honeytrap and change in electrical conductivity of the culture was monitored using a digital 3-in-1 TDS/EC/Temp meter (Labcare,India) post incubation 
periods. The alteration in the electrical conductivity of suspension was plotted against the incubation time and correlation studied with the change in percentage of bacterial cells.

\section{Effect of HS on adsorbed Pseudomonas}

Two sets of $2 \mathrm{ml}$ 'spiked' water samples were taken and exposed to control strips and honeytrap respectively and incubated for different time periods. Subsequently, strips were incubated overnight at $37^{\circ} \mathrm{C}$ on nutrient agar to assess the possible adsorption and inhibition of $P$. aeruginosa by control and SHS strips.

\section{Imaging and characterization}

The functionality of serine as an attractant was confirmed using an optical microscope (40X magnification). $200 \mu \mathrm{l}$ of overnight bacteria culture was placed on the glass slide with a honeytrap placed at one end of the glass slide. Bacterial adsorption on the device was observed via Field emission scanning electron microscopy (Fe-SEM) (Nova Nano FE-SEM 450) after exposing the strip $\left(1 \mathrm{~cm}^{2}\right)$ to vacuum gold sputter coater and the images were observed with $5.00 \mathrm{kV}$ accelerating voltage of electrons and at a magnification of $10,000 \mathrm{X}$.

\section{Result And Discussion}

\section{Design of the SHS bait}

A chemotactic trap with serine as an attractant, specific for P.aeruginosa(Moulton and Montie, 1979)was affixed in a contiguous manner with an inhibitory strip. This trap takes the advantage that it can autonomously attract, trap and destroy Pseudomonas in a co-ordinated mechanism as depicted in

\section{Scheme 1}

\section{Functioning of SHS}

A three pronged approach was used to verify the attraction, trapping, and destruction machinery of the SHS strip and each mechanism was monitored sequentially.

Attraction of cell by SHS

The SHS doped with $1 \mathrm{mM}$ serine was tested for its bacterial 'chemotactic' potential. Conventional mechanism of monitoring chemotaxis was modified using SHS strip on glass slide whereby serine of SHS induced active migration of cells (Fig. 1). With an increase in the incubation time, there was a clear demarcation and movement of theells towards SS owing to its chemoattractant property. The cell suspensions were exposed to different incubation periods and residual numbers of cells were enumerated.There was a perceptive increase in the cell concentration towards the serine end of the device within 15 min as compared to the control strip containing water. Negligible cells were observed near the 
CS. The structure of the paper enabled the movement of bacteria within the SHS strip thus contributing to real time removal of bacterial cells.

The other method used to confirm the effectiveness of SHS was by measuring the OD of the spiked water with a specific cell density. According to the Mcfarland standard, a cell density of $3 \times 10^{8} \mathrm{CFU}$ corresponds to 0.123 at $O D_{600}$. The strip was dipped approx $1 \mathrm{~cm}$ from the end of the sample and was kept for the designated incubation time (15 min, $45 \mathrm{~min}, 60 \mathrm{~min}, 90 \mathrm{~min}$ ). After each incubation, the strip was removed and the OD of the sample was taken at $600 \mathrm{~nm}$. Results confirmed that despite abundant load of cells, the strip removed about $96 \%$ of the total load after 2 hours of incubation (Fig. 2). The decrease in the residual cells was additionally confirmed by measuring the electrical conductivity. There was a consistent increase observed in the electrical conductivity with a smooth transition from $3788 \mathrm{mS} / \mathrm{cm}$ to $4052 \mathrm{mS} / \mathrm{cm}$ within 2 hours (Fig. 2). It has been earlier observed that an increase in conductivity is proportional to the corresponding decrease in cells in a suspension thus confirming the decrease in suspended bacterial cells (Harris and Patty, 1949).Furthermore, honeytrap indicated that the strip has a percent reduction value of $96 \%$ and a log reduction equivalent to 1.6 .

Trapping and removal by SHS

Reduction in suspended bacterial cells by the honeytrap was further confirmed using SEM. Approximately $1 \mathrm{~cm}^{2}$ cutouts were made $2 \mathrm{~cm}$ away from the SS (SSc) and HS (HSc) ends and analyzed (Fig. 3). Bacterial cells were observed in the SSc cellulose fibers within $30 \mathrm{~min}$ of incubation (Fig. 3a) whereas no bacterial cells were observed in HSc (Fig. 3d). The pores of the strip allow capillary action and enabled the bacteria to diffuse towards the HS end. After $60 \mathrm{~min}$, the elevated cell numbers was observed at the SSc strips (Fig. 3b) and comparatively fewer bacterial cells could be observed in HSc (Fig. 3e), thus indicative of honey susceptibility

A lesser number of cells in cutout from the honey end, HSc may either indicate a slower diffusion rate or the inhibitory activity of honey. Bacteria have been found to alter their size and shape in response to stress factors and this phenomenon could be correlated with the morphological changes and clumping observed in Pseudomonassignifying plausible cell death (Brudzynski and Sjaarda, 2014; CombarrosFuertes et al., 2020)(Fig. 3a).

Qualitative analysis of Chemo-inhibitory effect of SHS on Pseudomonas

The medicinal use of pure honey has been known since ancient times but its application in therapeutics and as an antimicrobial has been recently employed (Albaridi 2019, Husain et al., 2019). Studies indicated a concentration range of $20 \%-25 \%$ has $100 \%$ antimicrobial efficacy with 24 hrs incubation(Shenoy et al., 2012). In this case, the chemo-inhibitory effect of the SHS strip was confirmed by a simple plate incubation method. The incubation time varied from 15-90 min. The effect of honey was markedly evident as significantly lesser growth was perceived with the time, associated with the progressive disappearance of growth from the serine side of the strip. 


\section{The Road Ahead}

$P$. aeruginosa is widely distributed in the environment. By selectively using the unique combination of organism specific chemo-attractant and inhibitor, the honeytrap ensures passive targeting of Pseudomonas cells facilitating their efficient removal from water. The experimental setup for honeytrap indicated that the strip has a percent reduction value of $96 \%$ and a log reduction equivalent to 1.6 thus, indicating a water treatment potency of more or less $90 \%-92 \%$.

Currently, many point of care device are available with a range of efficacy and target contaminants. Previously a microfluidic device had been designed based on the chemotactic behavior of E.coli for subsequent disinfection of contaminated water(Kim et al., 2015). Other household water disinfection devices are available but may present various disadvantages like higher cost and use of chemicals (Table 1), Some of the instruments use UV light as a sterilant, however it has been observed that UV light may lead to mutation of the microbial species already present in the source (Shibai et al., 2017). Hence, honeytrap presents itself with a unique green technology designed with already proven antimicrobials that do not have any deleterious effect on humans

Table 1

Comparative study of the current available water treatment devices in the market with the Honeytrap device.

\begin{tabular}{|llll|}
\hline TECHNIQUE & PRICE & $\begin{array}{l}\text { POWER } \\
\text { SOURCE }\end{array}$ & CONSTITUENTS \\
\hline $\begin{array}{l}\text { Nanofiltration based water } \\
\text { purifiers }\end{array}$ & $\begin{array}{l}\$ 20- \\
\text { Hyper Light Disinfection }\end{array}$ & Required & Filtration unit, purifier body \\
Robot & $\$ 1000$ & Required & $\begin{array}{l}\text { UVC lamps, reflector, iron body of the } \\
\text { product }\end{array}$ \\
\hline UV bottle sterilizer & $\$ 250$ & Required & $\begin{array}{l}\text { UV light source, normally plastic body } \\
\text { utilized }\end{array}$ \\
\hline Disinfecting chemicals & $\$ 10-$ & $\begin{array}{l}\text { Not } \\
\text { Required }\end{array}$ & Only chemicals used \\
\hline Dip Treat device (27) & $<\$ 12-$ & $\begin{array}{l}\text { Not } \\
\text { Required }\end{array}$ & $\begin{array}{l}\text { Filter paper, glucose, Moringaoleifera } \\
\text { cationic protein }\end{array}$ \\
\hline Honey Trap device & $<\$ 2-4$ & $\begin{array}{l}\text { Not } \\
\text { Required }\end{array}$ & Filter paper, serine, honey \\
\hline
\end{tabular}

As per WHO recommendations, a competent water treatment device should belong to the tier 2 and tier 3 category capable of curbing growth by $99-99.999 \%$. The products thus adjudged are expensive, may require a power source and sometimes leave traces of chemicals, which may be harmful over time. The prototype proposed in this research is based on green technology, cost effective, biodegradable and tends to destruct the targeted bacteria in situ. Although further research and testing is required to attain the finesse suitable for acting as a household water treatment device, the honeytrap device envisions an exciting arena towards the development of a new generation of inexpensive and sustainable. The 
prototype may be extended to attract and destroy other motile related species. As an extension to current technology, In addition to honey, other natural inhibitors may be incorporated to make a device effective against a greater microbial diversity.

\section{Declarations}

Funding: The work received no funding from any authority

COMPETING INTERESTS: The authors declare no competing interest from any source.

\section{AUTHOR CONTRIBUTIONS}

MD conceived the idea; HR and PP performed the experimental work; MD,DP and HR contributed to writing of the manuscript, HR and PP prepared figures and/or tables. MD and DP reviewed and approved the final draft.

\section{ACKNOWLEDGEMENTS}

The authors thank Mr. Bhupesh Sharma, Scientific officer, MRC, MNIT, Jaipur for his technical assistance in acquiring scanning electron microscopy images. Authors acknowledge Dr. Deepshikha Rathore for proofreading the document.

\section{References}

1. Albaridi NA. 2019. Antibacterial Potency of Honey. Int J Microbiol 2464507. https://doi.org/10.1155/2019/2464507

2. Alhogail S, Suaifan GA, Bikker FJ, Kaman WE, Weber K, Cialla-May D, Zourob MM. 2019. Rapid colorimetric detection of Pseudomonas aeruginosa in clinical isolates using a magnetic nanoparticle biosensor. ACS omega 4:21684-21688. https://doi.org/10.1021/acsomega.9b02080.

3. Brick T, Primrose B, Chandrasekhar R, Roy S, Muliyil J, Kang G. 2004. Water contamination in urban south India: Household storage practices and their implications for water safety and enteric infections. Int J Hyg Environ Health 207:473-480. https://doi.org/10.1078/1438-4639-00318

4. Brudzynski K, Sjaarda C. 2014. Antibacterial compounds of Canadian honeys target bacterial cell wall inducing phenotype changes, growth inhibition and cell lysis that resemble action of $\beta$-lactam antibiotics. PLoS One 9:e10696. https://doi.org/10.1371/journal.pone.0106967

5. Careaga M, Fernández E, Dorantes L, Mota L, Jaramillo ME, Hernandez-Sanchez H. 2003. Antibacterial activity of Capsicum extract against Salmonella typhimurium and Pseudomonas aeruginosa inoculated in raw beef meat. Int J Food Microbiol 83:331335. https://doi.org/10.1016/S0168-1605(02)00382-3

6. Chen JW, Lau YY, Krishnan T, Chan KG, Chang CY. 2018. Recent Advances in Molecular Diagnosis of Pseudomonas aeruginosa Infection by State-of-the-Art Genotyping Techniques. Front Microbiol 
9:1104. https://doi.org/10.3389/fmicb.2018.01104

7. Combarros-Fuertes P, M Estevinho L, Teixeira-Santos R, G Rodrigues A, Pina-Vaz C, Fresno JM, Tornadijo ME. 2020. Antibacterial action mechanisms of honey: Physiological Effects of Avocado, Chestnut, and Polyfloral Honey upon Staphylococcus aureus and Escherichia coli. Molecules 25:1252. https://doi.org/10.3390/molecules25051252

8. Cooper RA, Halas E, Molan PC. 2002. The efficacy of honey in inhibiting strains of Pseudomonas aeruginosa from infected burns. J Burn Care Rehabil 23:366-370. https://doi.org/10.1097/00004630200211000-00002

9. Dasgupta S, Gunda NSK, Mitra SK. 2016. Fishing, trapping and killing of Escherichia coli (E. coli) in potable water. Environ Sci 2:931-941. https://doi.org/10.1039/C6EW00200E

10. Fitzgerald GP, DerVartanian ME. 1969. Pseudomonas aeruginosa for the evaluation of swimming pool chlorination and algicides. Appl Microbiol 17:415-421. https://doi.org/10.1128/am.17.3.415421.1969

11. Galal-Gorchev H, Ozolins G. 1993. WHO guidelines for drinking-water quality. Water Supply 11:1-6.

12. George SE, Walsh DB, Stead AG, Claxton LD. 1989. Effect of ampicillin-induced alterations in murine intestinal microbiota on the survival and competition of environmentally released pseudomonads. Fundam Appl Toxicol 13:670-680. https://doi.org/10.1016/0272-0590(89)90325-4

13. Gobelius L, Hedlund J, Dürig W, Tröger R, Lilja K, Wiberg K, Ahrens L. 2018. Per- and Polyfluoroalkyl Substances in Swedish Groundwater and Surface Water: Implications for Environmental Quality Standards and Drinking Water Guidelines. Environ Sci Technol 52:4340-4349. https://doi.org/10.1021/acs.est.7b05718

14. Han AM, Oo KN, Midorikawa Y, Shwe S. 1989. Contamination of drinking water during collection and storage. Trop Geogr Med 41:138-140. PMID: 2527428

15. Harris JO, Patty RE. 1949. Conductivity studies of bacterial suspensions. J Bacteriol 57:67-71. https://doi.org/10.1128/jb.57.1.67-71.1949

16. Héry-Arnaud G, Nowak E, Caillon J, David V, Dirou A, Revert K, Munck MR, Frachon I, Haloun A, Horeau-Langlard D, Le Bihan J, Danner-Boucher I, Ramel S, Pelletier MP, Rosec S, Gouriou S, Poulhazan E, Payan C, Férec C, Rault G, Le Gal G, Le Berre R. 2017. Evaluation of quantitative PCR for early diagnosis of Pseudomonas aeruginosa infection in cystic fibrosis: a prospective cohort study. Clin Microbiol Infect 23:203-207. https://doi.org/10.1016/j.cmi.2016.11.016

17. Hussain MB, Kamel YM, Ullah Z, Jiman-Fatani AAM, Ahmad AS. 2019. In vitro evaluation of methicillin-resistant and methicillin-sensitive Staphylococcus aureus susceptibility to Saudi honeys. BMC Complement Altern Med 19:1-9. https://doi.org/10.1186/s12906-019-2603-8

18. Jamshaid M, Khan AA, Ahmed K, Saleem M. 2018. Heavy metal in drinking water its effect on human health and its treatment techniques-a review. Int J Biosci 12:223-240. http://dx.doi.org/10.12692/ijb/12.4.223-240

19. Kim M, Jung T, Kim Y, Lee C, Woo K, Seol JH, Yang S. 2015. A microfluidic device for label-free detection of Escherichia coli in drinking water using positive dielectrophoretic focusing, capturing, 
and impedance measurement. Biosens Bioelectron 74:1011-1015.

https://doi.org/10.1016/j.bios.2015.07.059

20. Lee HH, Hong SI, Kim D. 2014. Microbial reduction efficacy of various disinfection treatments on fresh-cut cabbage. Food Sci Nutr 2:585-590. https://doi.org/10.1002/fsn3.138

21. Martínez-Tomé $M$, Jiménez-Monreal AM, García-Jiménez L, Almela L, García-Diz L, Mariscal-Arcas $M$, Murcia MA. 2011. Assessment of antimicrobial activity of coffee brewed in three different ways from different origins. Eur Food Res Technol 233:497-505. https://doi.org/10.1007/s00217-011-1539-0

22. Mena KD, Gerba CP. 2009. Risk assessment of Pseudomonas aeruginosa in water. Rev Environ Contam Toxicol 201:71-115. https://doi.org/10.1007/978-1-4419-0032-6_3

23. Moulton RC, Montie TC. 1979. Chemotaxis by Pseudomonas aeruginosa. J Bacteriol 137:274-280. https://doi.org/10.1128/jb.137.1.274-280.1979

24. Müller TH, Montag T, Seltsam AW. 2011. Laboratory evaluation of the effectiveness of pathogen reduction procedures for bacteria. Transfus Med Hemother 38:242-250. https://doi.org/10.1159/000330338

25. Negi PS, Jayaprakasha GK, Jagan Mohan Rao L, Sakariah KK. 1999. Antibacterial activity of turmeric oil: a byproduct from curcumin manufacture. J Agric food Chem 47:4297-4300. https://doi.org/10.1021/jf990308d

26. Pachori P, Gothalwal R, Gandhi P. 2019. Emergence of antibiotic resistance Pseudomonas aeruginosa in intensive care unit; a critical review. Genes Dis 6:109-119. https://doi.org/10.1016/j.gendis.2019.04.001

27. Peixoto JRO, Silva GC, Costa RA, Vieira GHF, Fonteles Filho AA, dos Fernandes Vieira RHS. 2011. In vitro antibacterial effect of aqueous and ethanolic Moringa leaf extracts. Asian Pac J Trop Med 4:201-204. https://doi.org/10.1016/S1995-7645(11)60069-2

28. Pathak SP, Kumar S, Ramteke PW, Murthy RC, Bhattacherjee JW, Gopal K. 1994. Potability of water sources in relation to metal and bacterial contamination in some northern and north-eastern districts of India. Environ Monit Assess 33:151-160. https://doi.org/10.1007/BF00548595

29. Price D, Ahearn DG. 1988. Incidence and persistence of Pseudomonas aeruginosa in whirlpools. J Clin Microbiol 26:1650-1654. https://doi.org/10.1128/jcm.26.9.1650-1654.1988

30. Rutala W, Weber D. 1997. Water as a Reservoir of Nosocomial Pathogens. Infect Control Hosp Epidemiol 18:609-616. doi:10.2307/30141486

31. Shenoy VP, Ballal M, Shivananda PG, Bairy I. 2012. Honey as an antimicrobial agent against Pseudomonas aeruginosa isolated from infected wounds. J Glob Infect Dis 4:102. doi: 10.4103/0974-777X.96770

32. Shibai A, Takahashi Y, Ishizawa Y, Motooka D, Nakamura S, Ying BW, Tsuru S. 2017. Mutation accumulation under UV radiation in Escherichia coli. Scientific reports 7:1-12. https://doi.org/10.1038/s41598-017-15008-1

33. Sourjik V, Wingreen NS. 2012. Responding to chemical gradients: bacterial chemotaxis. Curr Opin Cell Biol 24:262-268. https://doi.org/10.1016/j.ceb.2011.11.008 
34. Wilkinson JM, Cavanagh HM. 2005. Antibacterial activity of 13 honeys against Escherichia coli and Pseudomonas aeruginosa. J Med Food 8:100-103. https://doi.org/10.1089/jmf.2005.8.100

\section{Figures}

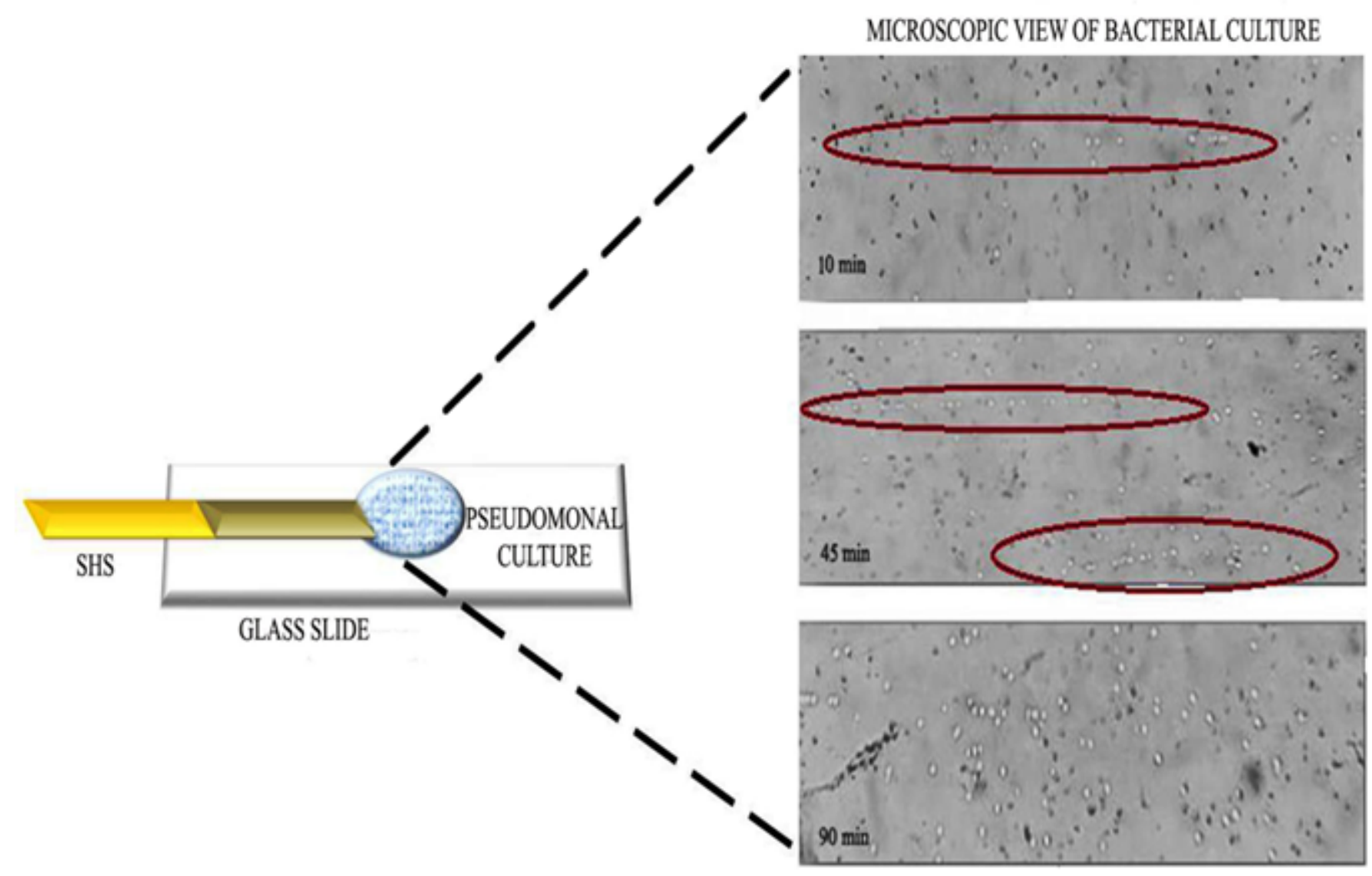

\section{Figure 1}

The chemotactic property of the honeytrap strip was verified by incubating it with a drop of culture containing Pseudomonal cells on a simple glass slide. Movement of cells in the droplet was monitored using an optical microscope. The picture clearly depicts bacterial lines (encircled in red) moving towards the strip in an ordained manner. Snapshot obtained at 90 min indicated the movement of large scale of cells towards the SHS strip. 


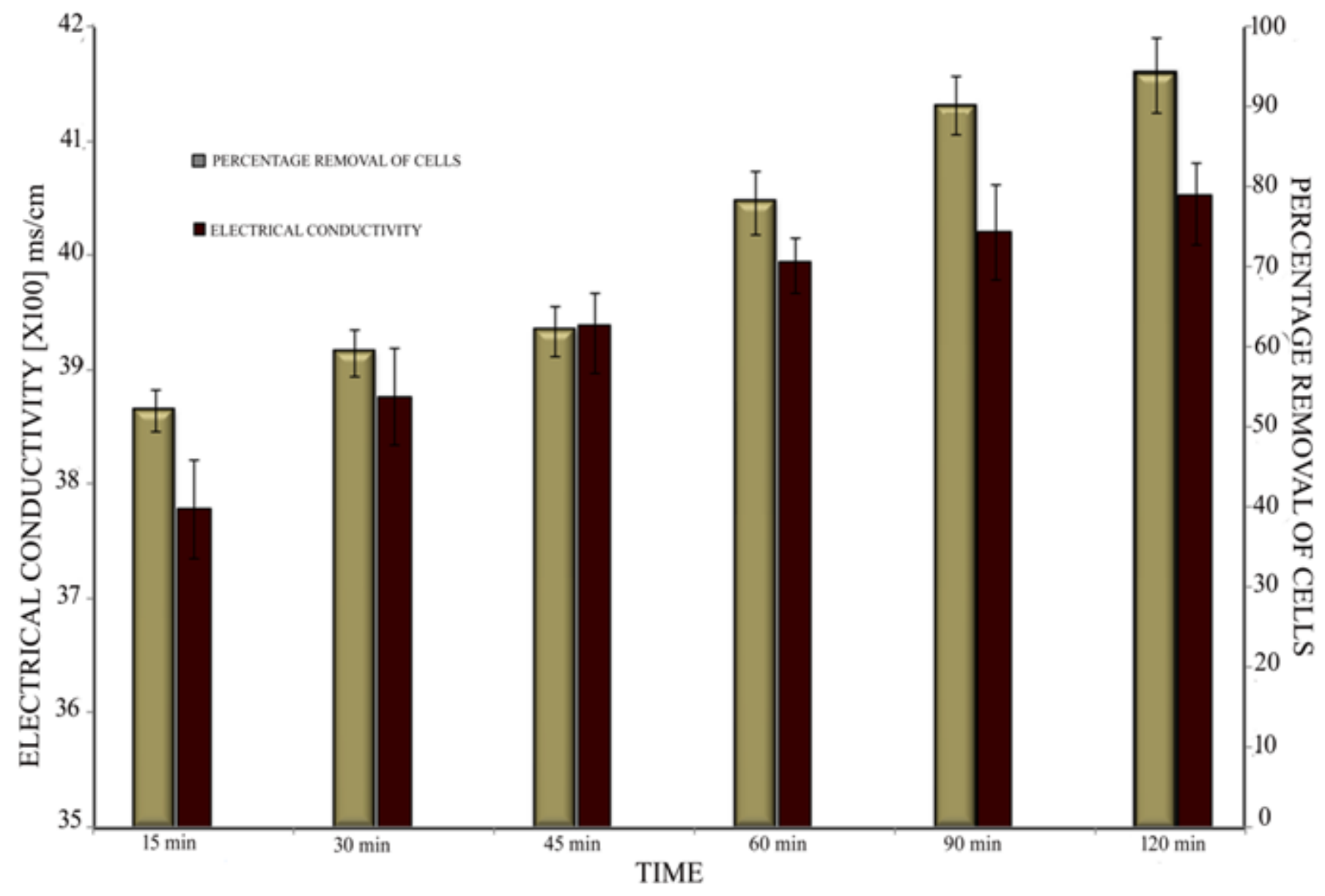

Figure 2

Graphical representation depicting the efficiency of the $1 \mathrm{mM}$ serine strip monitored at different time intervals against a standard bacterial suspension of $3 \times 108 \mathrm{CFU} / \mathrm{ml}$. Progressive increase in electrical conductivity was noted with increasing incubation time of the honeytrap device and spiked water samples concurrent with increase in the percentage of cells removed from the suspension. Error bars indicate the standard errors from three replicate readings taken for validation. 


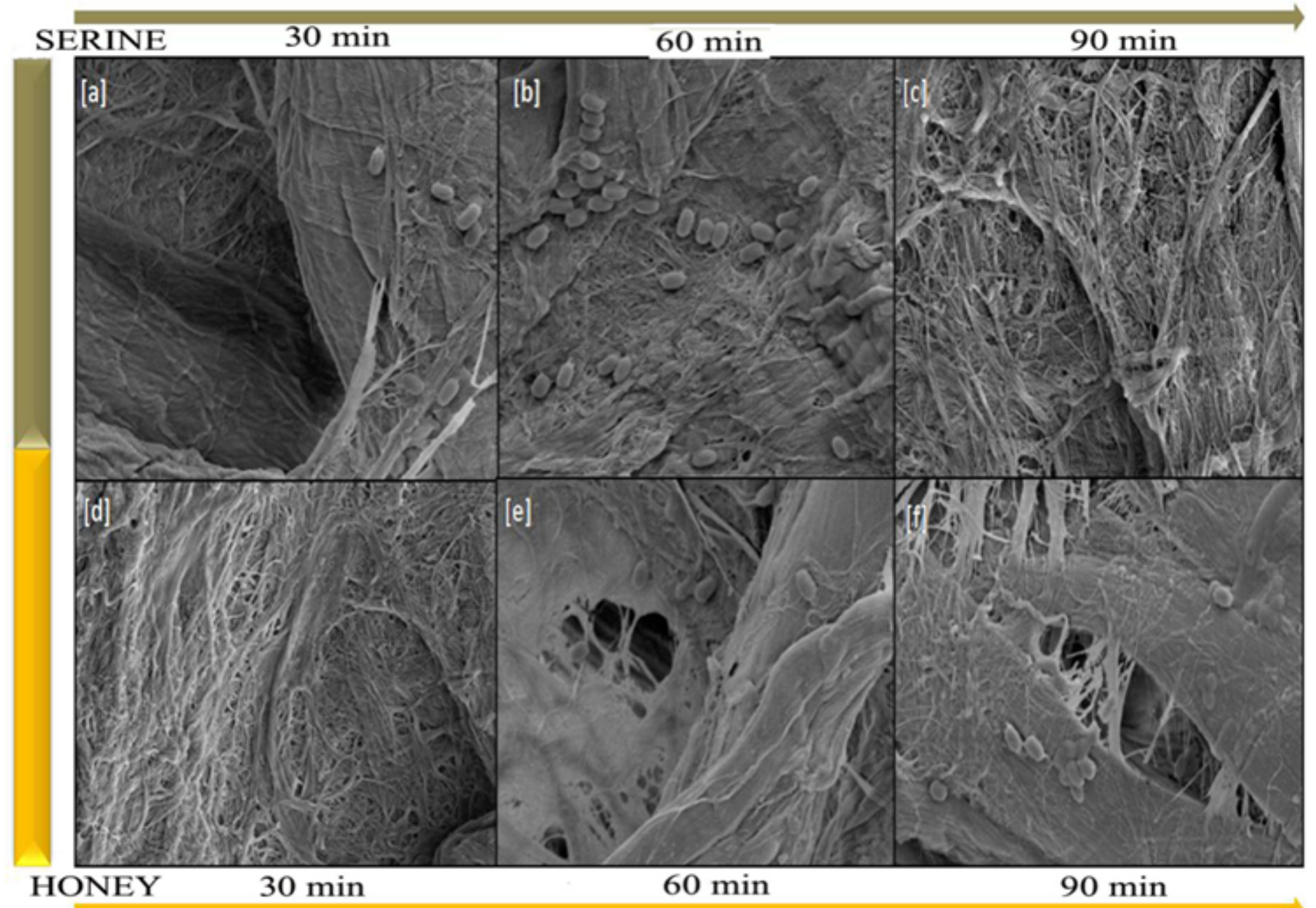

\section{Figure 3}

Scanning Electron Microscopy (SEM) of honeytrap strip exposed to bacterial culture. Fig (a), (b), (c), monitors the serine end of the strip whereas (d), (e), (f) represents the honey end of the of the strip at 30 min, 60 min, 90 min of exposure respectively. Distinct bacterial cells are observed in (a), (b) with the cells in (b) plausibly indicating a chemotactic steering effect. Morphological transitions due to exposure to honey is evident in (f) as portrayed by the filamentous outgrowth as well as clumping of the cells. All the outer SEM images are magnified upto $5 \mu \mathrm{m}$

\section{Supplementary Files}

This is a list of supplementary files associated with this preprint. Click to download.

- GraphicalAbstract.png 